\title{
Study on the Influence of Social Security on Household Consumption in Urban and Rural Areas
}

\author{
QIAN Yuzhuo \\ College of Economics and Management, Baicheng Normal University, Baicheng, 137000, China \\ email: 8438136@qq.com
}

Keywords: Social Security , Household Consumption in Urban and rural, Influence

\begin{abstract}
With the development of social economy, all kinds of industries are reforming and innovating, strengthening management, expanding scale and improving economic benefits. In recent years, the state has paid more and more attention to social security work and increased its investment in the social security industry. It has promoted the development of social security, improved the quality of life of the residents, promoted the overall consumption level of our country, and maintained the social security and stability. Therefore, it is necessary to probe into the influence of social security on the consumption of urban and rural families.
\end{abstract}

\section{Introduction}

With the marketization of the economy, people's material living standards and the level of spiritual civilization have improved significantly, but the survival and security of some old, weak, sick, disabled and other basic social personnel still need the attention of the society. The importance of social security is more prominent. Whether the social security system is perfect or not is directly related to the consumption level and quality of life of urban and rural residents in China, and affects the development of social economy. The social security work in our country has put forward higher requirements, and it is also a severe test to the social security work. Therefore, according to the specific situation, the influence of social security on the consumption of urban and rural families is analyzed, and effective strategies are adopted. To further improve the social security system, improve people's living standards, and promote the economic development of our country is worth exploring.

\section{Social Security System}

What is the Social Security System. Under the management of the government, the social security system is based on certain laws and regulations. Through the redistribution of national income, the social security system relies on the social security fund. To some citizens who are temporarily or permanently incapacitated to work and who have difficulties in their lives for various reasons, they will be given corresponding material assistance. In order to protect the most basic living needs of the residents, the funds of the social security system mainly come from collective insurance, individual insurance, state government assistance, compulsory savings and so on. The State shall provide relief to citizens whose standard of living falls short of the minimum standard of living, provide basic security of living for those who are temporarily or permanently unable to work, and gradually enhance the material and cultural welfare of all members of society. The essence of social security is to maintain social fairness and then promote the stable development of society. Whether the social security system is perfect or not has become one of the important symbols of social civilization progress[1].

Significance of Social Security. The Constitution of the people's Republic of China stipulates: "when a citizen of the people's Republic of China is old, ill, or incapacitated to work, The right to material assistance from the state and society. "this provides a legal basis for the establishment and improvement of the social security system in our country. The establishment of the social security system makes up for the deficiencies of the market economy," he said. It creates more opportunities for equal competition for enterprises, relieves workers' worries and promotes social harmony and 
stability. The social security system adjusts income distribution and maintains social fairness. Ensuring the basic human and social rights of members of society and promoting social harmony play a vital role. The right to social security is equal for all. Under the social security system, citizens have the right to education. The right to health and minimum security of living, the right of any member of society to equal access to social security in accordance with the conditions prescribed by law, without discrimination against vulnerable groups or in favour of the privileged, Through the social security mechanism, we should focus on the protection of the extremely poor in society. Social security is realized through social welfare, social insurance, social assistance, social preferential care and resettlement and other social security systems of different nature, role and form[2].

\section{The Influence of Social Security on the Consumption of Urban and Rural Families}

Guaranteed The Basic Living Consumption of the Low Income Population. In the urban and rural household consumer population, the social basic consumer group accounts for a large proportion, but each individual consumer demand for basic consumption is basically unchanged. It is impossible to improve the level of basic consumption by relying on the quantity and type of consumer goods by individual consumers, only by increasing the number of people who consume on a basic basis. Through social security, it provides basic livelihood and consumption security for the majority of low-income people. This part of the population is a very large group in the basic consumer population. The level of social security is directly related to the amount of consumption of basic consumer goods by low-income people, and the coverage of social security determines the growth rate of the basic consumer population. The social security system ensures the basic living consumption of low-income people and improves the development level of people's basic consumption[3].

The Influence of Social Security System on the Consumption of Urban and Rural Residents Due to Regional Differences. In different regions, the economic income is different, the economic development situation is different, the level of consumption and the understanding of social security are also different. The social security system in Northeast China was implemented earlier, and the economic situation of the families of the local residents has obviously changed. With the decrease of financial risk, the consumption consciousness of the residents is also increasing. The local government attaches great importance to social security work, the intensity of capital investment is great, the consumption level of local residents has been obviously improved, and the residents' trust in social security policy has also been raised[4]. Therefore, the social security system has played a positive role in promoting the consumption level of local urban and rural residents. But in the central and western regions, because the social security is still in the perfect stage, the local geographical environment features, and the economy is relatively backward. Coupled with the rising prices at present, local residents are worried about consumption. As a result, consumption awareness and consumption level are on the low side, and the role of the social security system has not been brought into full play. It can be seen that different regions, The influence of social security system on consumption level of urban and rural residents is obviously different.

The Influence of social Security Income Level on Household Consumption in Urban and Rural Areas. Social security income level of urban and rural household consumption expenditure is directly related to urban and rural social security, family income, to promote urban and rural household consumption expenditure, by contrast, social security income increases, city household consumption expenditure of rural household consumption expenditure is more than the growth rate of the overall level of China's social security system is still relatively low, the imperfect social security, income growth on the improvement of household consumption expenditure is not significant. Because of China's social security system is not perfect, so that urban and rural residents rely on old-age insurance and medical insurance and other social security can not completely relieve the majority of urban and rural households to menace from the rear, the increase in income retained through the way of saving for risk prevention, and ensure the safe and stable life in the future[5].

The Influence of Different Types of Social Security System on Household Consumption of 
Urban and Rural Residents. Different types of social security systems also have different effects on the consumption of urban and rural residents. For example, with the aging of the population in China, the proportion of the elderly increases. By increasing the expenditure of the old-age insurance, the old-age insurance can make the urban and rural residents have some protection and support for the elderly, increase the sense of security for the elderly, enhance the security and stability of the family life of the urban and rural residents, and make it possible to consume safely. To a certain extent, it promotes the consumption of urban and rural households. The medical insurance system provides protection for residents' health and medical care, and reduces and avoids the risks that urban and rural residents have to bear due to the problems of doctors and patients. It has promoted the safety and stability of urban and rural residents' lives. With the continuous increase of medical expenses in China, medical insurance has provided more protection for urban and rural residents, reduced the medical investment of urban and rural residents, and allowed them to spend more safely. Therefore, medical insurance helps to improve the consumption level of urban and rural residents[6].

The Impact of Price Changes on Household Consumption in Urban and Rural Areas. The changes in prices are closely related to social security. With the deepening of economic reform, the correlation between social security and price levels should become inevitable. The response to the price rise is obvious, and the increase in prices has an inhibitory effect on rural households' daily consumption. Urban households are accustomed to price changes, but they have little reaction to price changes, and household consumption tends to normalize. That is to say, price changes have less impact on urban households. On the other hand, price changes are mainly reflected in consumer goods. Rural residents have more demand for basic consumer goods, and rural residents are more affected by prices. However, the proportion of rural residents who are the object of social security is large. With the change of price, social security will inevitably change. The level of social security should fully reflect the changing factors of market price. Thus reducing the effect of price increase on household consumption in urban and rural areas and ensuring that consumer prices change within a reasonable range[7].

\section{Countermeasures and Suggestions for Perfecting Social Security System}

Narrowing the Consumption Gap Between Urban and Rural Residents. The establishment and perfection of the social security system is a difficult and complicated task. According to the specific situation of our country, it is necessary not only to make appropriate adjustments to the original social security expenditure system, but also to have a long way to go. We should shift the emphasis of social security from the urban to the rural areas, increase the investment of social security funds in rural areas, and improve the serious shortage of social security funds in rural households. Because of the geographical and economic structure of rural residents, The family income is much lower than that of the urban residents, the local social security system is not perfect, the social security benefits are low and even some rural residents in remote areas do not enjoy the social security treatment at all[8]. The gap in household consumption between urban and rural residents has increased. Therefore, governments at all levels should, according to the actual local conditions, start with each family and strengthen social security work, especially in order to further improve the medical security system in rural areas. To reduce and avoid the rural residents because they can not afford to pay expensive medical expenses and poverty phenomenon, through the improvement of the social security system, reduce the gap between urban and rural areas.

We Will Improve the System of Investment and Operation of Social Security Funds and the System of Supervision and Management. Funds are the material basis for the operation and development of the social security system. Therefore, the rational use of funds also needs a strict system to rely on. On the premise of ensuring social security expenditure and the safety of funds, surplus funds can be used for investment. To improve the utilization rate and efficiency of funds, to establish and improve the investment and operation system of social security funds, to ensure the safety of social security funds and to play the most important role, and to establish special investment and research institutions for social security funds, To ensure the safety of funds and the 
safety of funds is one of the most important tasks in social security. To perfect the supervision system of social security funds and the mechanism of early warning and monitoring, and to establish a comprehensive supervisory system of legal supervision, judicial supervision and administrative supervision, We should fully mobilize the masses and advocate public supervision. Every citizen has the right to supervise the social security fund, discover illegal activities such as private purse, misappropriation of funds, corruption, and so on, and report them to the relevant departments in a timely manner. Relevant departments should timely intervene in the investigation, make joint action between internal and external supervision, work together to make the social security system play a greater role, and continuously improve the living standards of urban and rural residents[9].

Enhancing the Consumption Confidence of Urban and Rural Families. Through the continuous improvement of the social security system, the existing problems are analyzed, and the weak links in the original system are made up and corrected, so that the social security system covers a wider range and involves more diverse people. Continue to expand the scope of social security work so that all kinds of families in different regions, at different levels and at different income levels can enjoy social security. Feeling the superiority of the socialist system and the warmth of the great family of the motherland, ensuring that the process of implementing the social security system is fair and just, proceeding from the reality, comprehensively examining the level of per capita income and consumption in different regions and paying attention to regional differences, To formulate social security standards that conform to the characteristics of different regions, so that families at different levels can realize the sense of security brought about by the social security system, make the social security system more targeted and effective, and relieve the worries of urban and rural residents' consumption. Strengthen consumption confidence, improve the consumption level of urban and rural families, promote the virtuous cycle of our economy, and promote the vigorous development of our economy.

Perfect the Social Security System. The system is not only the basis for doing social security work well, but also the legal constraint for standardizing all kinds of improper acts. On the basis of the original integration system of urban and rural social security system, the social security system should be perfected. Institutionally eliminating the gap between urban and rural families in the scope of social security, solving the problems of inequality and imbalance between urban and rural families, increasing the coverage of social security, and gradually solving the problem of low social security income in remote areas through preferential policies. And insufficient funds. Improve social security programs in rural areas, such as work-related injuries, medical treatment, and childbearing, so that rural families can enjoy the same social security treatment as urban families, and formulate social security policies that conform to the aging of the social population. To reduce the heavy economic burden borne by urban and rural families due to the old-age care. Establish and improve the social security information platform to realize the social security fund mutual aid, social security information sharing, urban and rural residents' social security transfer and continuation of modern functions.

Improve the Structure of Social Security Income. In the process of the continuous improvement and development of the social security system, although the social security system is constantly tending towards the countryside, the social income and consumption level of the rural residents are still far lower than that of the urban families, and only to narrow the income gap between urban and rural households. It is necessary to improve the expenditure structure of social security and increase public finance's investment in social security, especially in rural areas. Reduce rural residents' consumption worries, make them more secure and secure. At the same time, strictly enforce the use of social security funds in rural areas, and prevent the illegal behavior of squeezing social security funds without authorization, withholding and seizing the social security income that should have been issued to the residents. Strict punishment, according to the seriousness of the circumstances, to give the necessary punishment and punishment, optimize social security expenditure, so that social security funds in urban and rural families play a greater role. 


\section{Conclusion}

The social security is the product of the economic development of our country in a certain period, and it is of great significance to improve the consumption level of the residents and promote the economic development of our country. This paper expounds the concept and significance of social security system, from the protection of low income people's basic living consumption, the social security system because of regional differences on urban and rural residents' consumption, the impact of social security system on the consumption of urban and rural residents. The influence of social security income level on household consumption in urban and rural areas, and the influence of different social security systems on household consumption in urban and rural areas. This paper analyzes the influence of the social security system on the household consumption in urban and rural areas in terms of the influence of price level changes on the consumption of urban and rural households, and it can take measures to narrow the consumption gap between urban and rural residents. To improve the investment and management system of social security fund, to enhance the consumption confidence of urban and rural families, to improve the social security system, to improve the structure of social security income, to increase social security efforts, and to reduce the gap between urban and rural areas. We will improve the consumption capacity of urban and rural residents and promote the smooth flow of the economy. Let us work together to contribute to the rapid development of our economy.

\section{References}

[1]ZHANG Aiping. Study on the Influence of Social Security on Household Consumption in Urban and Rural Areas[J].Human Resource Management,2017(08):399-400.

[2]MA Liya. Study on the Influence Mechanism and Effect of New Rural Cooperative Medical System on Rural Family Consumption[D].Southwest Finance,2016.

[3]WANG Yingnan. Study on the Effect of Fiscal Social Security Expenditure on the Consumption of Urban and Rural Residents in China[D].Journal of Social Science of Harbin Normal University,2016.

[4]CHEN Luxia. A Comparative Analysis of the Effect of Social Security Expenditure on the Consumption Tendency of Urban and Rural Residents[D].Collected Essays on Finance and Economics,2015.

[5]GAO Chang. Study on the Influence of Social Security on Household Consumption in Urban and Rural Areas[J].Modern Economic Information,2015(20):121.

[6]LI Xiaoma. The influence of Social Security system on the consumption of Urban and Rural families[J].Modern Economic Information,2015(12):158.

[7]WANG Yingnan,ZHAO Chenguang. Study on the Main Influence of Social Security on the Consumption of Urban and Rural Families[J].Money China,2015(02):286.

[8]GUANG Hao. The Influence of Social Security on the Consumption of Urban and Rural Residents[J].Economic Forum,2013(06):149-151.

[9]FANG Kuangnan,ZHANG Ziyi. Study on the Influence of Social Security on Household Consumption in Urban and Rural Areas[J].Statistical Research,2013,30(03):51-58. 